\title{
Pathotypes Detected Among Populations of Pratylenchus neglectus Collected From Montana
}

\author{
Riyadh T. Al-Khafaji, ${ }^{1,2}$ Erin E. Gunnink Troth, ${ }^{1}$ Kris N. Lambert, ${ }^{3}$ Jeffrey A. Johnston, ${ }^{1}$ and Alan T. Dyer ${ }^{1, \dagger}$ \\ ${ }^{1}$ Department of Plant Sciences and Plant Pathology, Montana State University, Bozeman, MT, U.S.A. \\ ${ }^{2}$ Plant Protection Department, University of Baghdad, Baghdad, Iraq \\ ${ }^{3}$ Department of Crop Sciences, University of Illinois, Urbana, IL, U.S.A.
}

\begin{abstract}
The root lesion nematode, Pratylenchus neglectus, is one of the most damaging nematodes to affect wheat worldwide. The nematode is widely distributed in Montana, primarily affecting winter wheat within the state. Managing the nematode primarily involves rotation to resistant and moderately resistant crops (peas, lentils, and barley). A nematode survey was conducted across the state nearly 10 years after an initial survey, to reassess the nematode threat and assess the impact of changing trends in crop rotations. To assess the broad applicability of rotation crops to control P. neglectus across Montana, greenhouse trials were conducted to challenge rotational crops using eight populations of $P$. neglectus

collected from geographically diverse locations across the state. In the trials, conducted with four Montana crops, a significant interaction was detected between crop and nematode population (analysis of variance $P<0.001)$. Populations from Hill, Dawson, and Chouteau counties were found to be pathogenic on barley. Male nematodes were detected in seven of the eight pot culture populations, and these were confirmed to be $P$. neglectus by morphological and molecular methods. These results suggest a re-evaluation of barley and lentils as a management option for P. neglectus in Montana, as pathotypes for each exist within the state.
\end{abstract}

Root lesion nematodes (RLNs) are serious pests that infest wheat roots and limit crop productivity (Smiley et al. 2004, 2005a, b; Thompson et al. 2008). The primary species affecting wheat are Pratylenchus crenatus Loof, P. neglectus (Rensch) Filipjev \& Schuurmanns Stekhoven, $P$. penetrans Cobb, and P. thornei Sher and Allen (Nickle 1991). Among these, $P$. neglectus and $P$. thornei are the primary species affecting wheat in the western United States (Smiley et al. 2008). Both species are migratory endoparasites (Smiley et al. 2005a, b; Thorne 1961) that can complete their entire lifecycle within the root system of the host plant (Williams et al. 2002). Yield losses for $P$. neglectus are reported as high as $37 \%$ in the Pacific Northwest region of the United States, whereas those for $P$. thornei are reported as high as 50\% (Smiley et al. 2005a). In Montana, a survey conducted in 2006 to 2007 (May et al. 2016) found damaging populations of $P$. neglectus primarily occurring in winter wheat production areas of the state; $P$. thornei was not detected.

A few researchers have reported potential races or pathotypes for RLN species. These primarily related to $P$. penetrans on tobacco and potato (France and Brodie 1996; Olthof 1968) and P. neglectus on alfalfa (Griffin 1991). Several sources of resistance to P. neglectus have been reported for wheat (Fanning et al. 2018; May et al. 2016; Thompson et al. 2016), but to date there have been no reports of variation in virulence of the pathogen relative to these resistances (Fanning et al. 2018; Sheedy et al. 2015). It is unclear whether this is a result of a lack of variation within the pathogen species or is attributable to limited experimental testing. Considerable variation in reproductive success has been reported on wheat and barley (Fanning et al. 2018; Gair et al. 1969; Sharma et al. 2011a, b; Smiley et al.

${ }^{\dagger}$ Corresponding author: A. T. Dyer; adyer@montana.edu

Funding: This research was supported by funds from the Montana Wheat and Barley Committee, Republic of Iraq, and U.S. Department of Agriculture (Hatch project 1002597).

The author(s) declare no conflict of interest.

Accepted for publication 20 June 2019.

(C) 2019 The American Phytopathological Society
2004, 2013; Taylor et al. 2000). The role that virulence plays in the variation in reproduction described in these reports is unclear.

Although the incorporation of resistance to RLN in wheat is uncommon in the United States, the use of nonhost rotational crops to manage RLN populations has been highly successful (Smiley et al. 2004, 2005b; Taylor et al. 2000). RLNs are successfully managed through resistant crop rotations and fallowing of affected fields (Florini et al. 1987; May et al. 2016), but the literature is conflicted on the efficacy of certain rotational crops, especially barley (Fanning et al. 2018; Gair et al. 1969; Riga et al. 2008; Sharma et al. 2011a, b; Smiley and Nicol 2009). This is at least partly attributable to variation in genetic resistance among cultivars (Keil et al. 2009; May et al. 2016). To date, no studies have yet examined variation in pathogenicity among $P$. neglectus populations for barley as the possible source of the conflicting reports.

In 2006 and 2007, a survey was conducted in Montana to assess the distribution and importance of the RLN, P. neglectus (May et al. 2016). This work was invaluable, as it showed for the first time that $P$. neglectus occurred in significant numbers throughout Montana, causing particularly heavy losses in winter wheat production areas (May et al. 2016). Since 2007, cropping systems in Montana have significantly changed, partly as a result of the economic pressures RLN placed on wheat monocultures and partly attributable to changes in the economics of legumes versus small grains. Pulses, which are reportedly resistant to $P$. neglectus, amount to over 490,000 hectares today, as opposed to approximately 125,000 hectares in 2007 (NASS 2016). Since the 2006 to 2007 survey, anecdotal reports of variation in responses of RLN populations to rotation have occurred. These reports raised concerns about the use of rotational crops as a management tool and suggested that their use had been more complex than previously reported in the literature. The variation in host genetics of rotational crops (Keil et al. 2009; May et al. 2016), as well as variation in nematode pathogenicity, call for further examination. The purpose of this work was to assess the overall impacts crop rotations have had on Montana's RLN populations since the initial survey and, for those instances where damaging populations of RLN persist, to characterize their pathogenicity across common rotational crops grown in Montana. For sampled fields, information on cereal cyst nematode and other plant parasitic nematodes was also sought, as occasional sightings have been recorded (Dyer et al. 2015; Smiley 2016). 


\section{Materials and Methods}

A survey of plant parasitic nematodes in Montana's small grain acreage was conducted in 2015 and 2016 across 11 counties chosen based on their large acreages of small grain production and geographic location in Montana; that is, they well represented the main small grain-growing regions of the state (NASS 2016). The surveyed counties represent approximately $40 \%$ of total wheat acreage in any given year (NASS 2016). Fifty-five fields were surveyed in 2015, and 53 were surveyed in 2016. The 11 counties surveyed were Bighorn, Carter, Chouteau, Dawson, Gallatin, Hill, Judith Basin, Liberty, Teton, Toole, and Yellowstone. Samples were taken from 15 June to 31 July in 2015, and from 1 May to 7 June in 2016. For each county, five wheat and/or barley fields were chosen. For each field, 20 subsamples were gathered to generate a composite bulk sample, totaling a minimum mass of $2,000 \mathrm{~g}$. Subsamples were gathered by sampling at least $100 \mathrm{~m}$ from the edge of field, in a circular pattern at least $100 \mathrm{~m}$ in diameter. For each subsample, 2.5-cm-diameter soil cores were taken, to a depth of $30 \mathrm{~cm}$ using a soil sampler with footstep (JMC Environmentalist's Subsoil Probe). Sampling locations were chosen randomly, eschewing areas that displayed compaction by equipment (e.g., tractors, combines, trucks, etc.) or were affected by a body of water such as a pond or ditch. Collected samples were kept in plastic coolers during transport and kept refrigerated at $5^{\circ} \mathrm{C}$ in the laboratory until nematodes could be extracted, which occurred within 4 weeks of sample collection. Plant parasitic nematodes were extracted via three methods: Whitehead-Hemming tray (May et al. 2016; Whitehead and Hemming 1965), sucrose centrifugation (Jenkins 1964), and soil sieving (Cobb 1918).

Nematode extraction methods. For all extraction methods, 20 subsamples from one field were mixed together to make a bulk sample, and a coarse sieve $(4.76 \mathrm{~mm})$ was then used to remove large stones, gravel, and organic matter. The Whitehead-Hemming method of extracting migratory nematodes utilized a 200-g sample taken randomly from the bulked sample. This was spread on a Kimwipe laboratory tissue $(30 \times 30 \mathrm{~cm}$; Kimtech) over a plastic mesh screen (1-mm openings) on a metal frame (phosphor-bronze gauze with 25-mm openings), resting in a pool of shallow water in plastic trays (dimensions: $43 \times 34 \times 10 \mathrm{~cm}$ ). Extractions occurred over $48 \mathrm{~h}$ at $20^{\circ} \mathrm{C}$. The nematodes were then concentrated by passing the nematode suspension through a $20-\mu \mathrm{m}$ mesh sieve, and then rinsing the captured nematodes into $50-\mathrm{ml}$ Falcon tubes using $50 \mathrm{ml}$ of tap water.

The second method for the extraction of migratory nematodes, sieving and sucrose centrifugation, utilized a 100-g sample from the mixed bulk soil. This was mixed with $500 \mathrm{ml}$ of sterile tap water by pouring the suspension between two beakers 10 times. A beaker with the soil sample was then whisked using a stainless laboratory spatula and heavy particles were allowed to settle for $15 \mathrm{~s}$. The resulting suspension was then poured through stacked U.S. standard testing sieves, size No. 20/No. $500(841 / 25 \mu \mathrm{m})$. Gentle tapping on the side of the No. 500 sieve was done to aid drainage. A water bottle was used to gently wash nematodes and to transfer them into a 50-ml centrifuge tube. Water was added to the tubes to equalize volumes at $40 \mathrm{ml}$. The resulting tubes were spun at $339 \times g(1,700 \mathrm{rpm})$ for $5 \mathrm{~min}$. The supernatant was removed, leaving $5 \mathrm{ml}$ of water and pellet. Tubes were then filled with sucrose solution at a concentration of $454 \mathrm{~g}$ of sugar/liter of deionized water at room temperature. A spatula was used to break up the pellet of soil, mixing it into suspension, and tubes were centrifuged again at $117 \times g(1,000 \mathrm{rpm})$ for $60 \mathrm{~s}$. Finally, the supernatant containing the nematodes was poured through the No. 500 sieve to separate the nematodes from the sucrose, gently rinsed with tap water, and decanted into vials.

The third nematode extraction method, sieving for cyst nematodes, targeted sedentary nematodes. A 200-g subsample of the mixed bulk soil was mixed with $500 \mathrm{ml}$ of tap water using a spatula. The large particles in the suspension were allowed to settle for $10 \mathrm{~s}$, and the remaining supernatant was poured through No. 35/No. 60 (500/ $250 \mu \mathrm{m})$ stacked sieves. The collected material on the fine sieve was rinsed gently with tap water and transferred to labeled vials to await examinations for cysts.
Greenhouse experiments and nematode maintenance. Seven RLN populations collected from different geographical regions in Montana during the survey were used in the study, named by county of origin: Carter County, Chouteau County, Dawson County, Gallatin County (P2), Hill County, Pondera County, and Yellowstone County. These populations were used to assess RLN variation within the state. Each population was collected from a field where the populations were high and geographically isolated from the other collection sites. An additional population, Gallatin County (P1), was included in the study. This population was used in previously reported studies (May et al. 2016). The populations were maintained in pot cultures in the greenhouse using the winter wheat cultivar Yellowstone prior to use.

A set of commonly grown rotational crops were used to determine the variation in pathogenicity of $P$. neglectus from different counties throughout Montana (Barker et al. 1985; Sasser 1972). Four crops (barley, pea, lentil, and wheat) were used. Three cultivars of barley (Harrington, Haxby, and Merit), one pea cultivar (Delta), one lentil cultivar (Richlea), and one wheat cultivar (Yellowstone: positive control), were used as the crop treatments. These were challenged with each of the eight RLN populations. The trial was run as a randomized complete block design with 18 replicates, blocked across three time points and planted 1 month apart (six replicates at each time point). The trial was repeated once. A thermo-hygrometer was used to record the temperature and relative humidity in the greenhouse at $21.1^{\circ} \mathrm{C}$ during the day and $18.3^{\circ} \mathrm{C}$ at night, with a $16-\mathrm{h} / 8-\mathrm{h}$ day/night photoperiod. Experimental treatments were planted to one cone-tainer $(20.7 \mathrm{~cm}$ height and $4 \mathrm{~cm}$ diameter). These tubes were filled with sufficient soil from the appropriate pot cultures to achieve between 200 and 500 nematodes per cone-tainer. This soil was supplemented with MSU mix soil (a steam-pasteurized 1:1:1 mixture of topsoil, peat moss, and concrete sand, augmented with the wetting agent Aqua-Gro 2000G) to fill the cone-tainers to the rim. Initial population densities were determined for each trial by producing six additional cone-tainers per nematode population, from which nematode populations were immediately extracted and enumerated. All nematode counts for greenhouse trials used the WhiteheadHemming nematode extraction method.

Morphological nematode identification and quantification. Classical morphological characteristics were used to identify nematodes to genus by using $10 \times$ and $40 \times$ magnifications on a Nikon Eclipse 50i microscope (Melville, NY) (Handoo et al. 2014; Loof and Luc 1990; Nickle 1991; Siddiqi 1963; Van den Berg et al. 2014; Wouts and Knight 1993). A Leica 10445929 0.5× dissecting microscope was used to check samples for cereal cysts. Nematodes were removed for examination by using a dental pick (K-Files, size 08, $25 \mathrm{~mm}, 07-0871558$, Patterson brand) and dissecting microscope. A McMaster Nematode Counting Slide (Chalex Corporation, Wallowa, OR) was used to count nematodes. The counting chamber was filled with nematode suspension $(2 \mathrm{ml})$ and examined using the Nikon Eclipse 50i microscope. For the statewide nematode survey, resulting counts were converted to nematodes per kilogram of soil and adjusted to account for soil moisture. Percent soil moisture was determined by drying $100 \mathrm{~g}$ of fresh soil at $70^{\circ} \mathrm{C}$ for $48 \mathrm{~h}$. Processing of samples occurred within 4 weeks of collection date (May et al. 2016). For greenhouse trials, counts were multiplied by total extraction volume $(50 \mathrm{ml})$ to calculate the number of RLNs per cone (May et al. 2016). The resulting value from these counts divided by the initial counts $\left(\mathrm{P}_{\mathrm{f}} / \mathrm{P}_{\mathrm{i}}\right)$ for each population was referred to as the reproduction factor (heretofore referred to as $\mathrm{Rf}$ ).

Molecular nematode identification. For molecular identification of nematode species, a single-nematode DNA extraction protocol was adapted from Dr. Kelley Thomas (University of New Hampshire Department of Molecular Cellular and Biomedical Sciences). For this, glass slides were sterilized with $70 \% \mathrm{ETOH}$ and washed with DNA Away (Molecular BioProducts Inc., San Diego, CA). The individual nematodes were then placed on the clean slides and their exteriors were rinsed by dripping them with $5 \mu$ l of deionized water, followed by drying using compressed air. The nematode was then cut into halves with a pipette tip on the slide and suspended in $5 \mu \mathrm{l}$ 
of Worm Lysis Buffer (1 M of Tris $[10 \mu \mathrm{l}], 1 \mathrm{M}$ of $\mathrm{MgCl}_{2}[2.5 \mu \mathrm{l}]$, $1 \mathrm{M}$ of KCl [50 $\mu \mathrm{l}]$, Tween 20 [4.5 $\mu \mathrm{l}], 1 \%$ [wt/vol] gelatin [50 $\mu \mathrm{l}]$, $20 \mathrm{mg} / \mathrm{ml}$ of Proteinase $\mathrm{K}[3.3 \mu \mathrm{l}]$, and sterile distilled water $[879.7 \mu \mathrm{l}])$. The resulting tissue suspension was pipetted from the slide into an Eppendorf tube with an additional $15 \mu$ l of lysis buffer. This was left for $10 \mathrm{~min}$ at room temperature, incubated at $60^{\circ} \mathrm{C}$ for $1 \mathrm{~h}$, heated to $95^{\circ} \mathrm{C}$ for $15 \mathrm{~min}$, and finally cooled to $4^{\circ} \mathrm{C}$. From the resulting DNA extraction, $2 \mu l$ of DNA template was used for PCR amplifications for small subunit (SSU) rDNA sequencing and $P$. neglectus barcoding.

For SSU rRNA PCR and sequencing, the SSU amplification protocol from Holterman et al. (2006) was followed. This involved amplification of two overlapping fragments. The first fragment was amplified using the primer 988F (5'-ctcaaagattaagccatgc- $\left.3^{\prime}\right)$ and the primer 1912R ( $5^{\prime}$-tttacggtcagaactaggg- $\left.3^{\prime}\right)$. The second fragment was amplified using primers $1813 \mathrm{~F}$ (5'-ctgcgtgagaggtgaaat- $\left.3^{\prime}\right)$ and 2646R (5'-gctaccttgttacgactttt-3'). Gel-purified amplification outputs were sent to MCLAB (San Francisco, CA) for sequencing. Resulting sequences were then compared with published SSU rDNA sequences to identify genera and species using BLAST (National Center for Biotechnology Information 2019) and the GenBank database (Holterman et al. 2006). Six novel SSU rDNA sequences for male $P$. neglectus were submitted to GenBank under the following accession numbers: MK208879 to MK208884.

In addition to the sequencing methods previously described, identification of Pratylenchus species was conducted following a barcoding protocol (Al-Banna et al. 2004) using single-nematode DNA extractions described above. For males of each population, species identification was conducted for five individual males. Resulting PCR products were size fractionated on $1 \%$ agarose gel with a positive $P$. neglectus control and a 100-bp ladder. Bands were visualized using a UVP Benchtop UP Transilluminator (UVP LLC, Upland, CA).

Statistical analysis. Multifactor analyses of variance (ANOVAs) were conducted using linear models, which included crop, RLN population, interaction between crop and RLN population, and trial. Analysis was conducted for all trials using RStudio version 3.2.3 R (RStudio Team 2016); linear modeling used the $\mathrm{lm}$ function in $\mathrm{R}$ (with the Integrated Development Environment; R Core Team 2016). The Rf was natural-log transformed after adding 1 to the values, as the data were non-normal. The resulting values were normally distributed, which were used for subsequent analysis. Where the ANOVA indicated significant treatment differences, a Fisher's protected least significant difference $(\alpha=0.05)$ was generated to compare treatment means (Devore and Peck 1997). For the crop rotation trials, the two trials were assessed for homogeneity of variance using Levene's test in $\mathrm{R}(\alpha<0.05)$. The trials did not violate the assumption of homogeneity of variance and provided similar conclusions; therefore, the two trials were combined into one data set to simplify discussion. The proportion of male nematodes within RLN populations was arcsine square root transformed and then analyzed using a single-factor ANOVA.

\section{Results}

Survey of Montana's parasitic nematodes. Nematodes extracted via the Whitehead-Hemming and the sucrose-centrifugation methods correlated significantly for $P$. neglectus in both $2015\left(R^{2}=0.33, P<\right.$ $0.001)$ and $2016\left(R^{2}=0.50, P<0.001\right)$, and for Tylenchorhynchus and Tylenchus species in $2015\left(R^{2}=0.17, P<0.001\right.$ and $R^{2}=$ $0.73, P<0.001$, respectively $)$ and $2016\left(R^{2}=0.44, P<0.001\right.$ and $R^{2}=0.17, P<0.001$, respectively). As such, only nematode counts resulting from the Whitehead-Hemming method are reported. The sole exception is for cyst nematodes, where the sieving extraction results are reported. The nematode species identified in those years are presented in Table 1. In both 2015 and 2016, damaging populations of $P$. neglectus $(>1,000 / \mathrm{kg}$ of dry soil) were found in $17 \%$ fields occurring in Big Horn, Gallatin, Chouteau, Dawson, Hill, and Teton counties, during early to midsummer. Cyst nematodes, a significant concern, were detected in only 11 fields. Heterodera avenae was detected in 10 of these fields, and H. filipjevi was detected in one field.
Average populations were low (H. avenae $=14$ to 27 nematodes $/ \mathrm{kg}$ soil, $H$. filipjevi $=0$ to 27 nematodes $/ \mathrm{kg}$ soil).

Variation in pathogenicity across rotational crops in greenhouse experiments. ANOVA showed significant differences for nematode Rf across $P$. neglectus populations averaged across all crops tested $(P<0.001)$, with the population from Hill being the most virulent (mean $\mathrm{Rf}=14.1$ ) and the populations from Yellowstone and Gallatin (P1) being the least virulent (mean $\mathrm{Rf}=2.0$ and 2.3 , respectively). Among crop species there was significant variation in susceptibility $(P<0.001$, Table 2$)$. Peas were consistently nonhosts across all RLN populations (mean $\mathrm{Rf}=0.5$, Table 2 ). Lentils were next lowest, with a mean $\mathrm{Rf}$ of 2.0 (Table 2). Of the rotation crops tested, barley averaged the highest $\mathrm{Rf}$ (mean $\mathrm{Rf}=4.1$ ); in particular, Haxby was the most susceptible barley cultivar tested $(\mathrm{Rf}=5.2)$, whereas Merit and Harrington demonstrated lower susceptibility $(\mathrm{Rf}=3.7$ and 3.5, respectively). A significant interaction between nematode populations and host crops was detected $(P<0.001$, Table 2$)$. The average $\mathrm{Rf}$ on the wheat positive control was 13.9. On wheat, there was particularly strong reproduction among populations from Hill (mean $\mathrm{Rf}=$ 44.3), Carter (mean $R f=11.2$ ), Chouteau (mean $R f=16.1$ ), and Gallatin $(\mathrm{P} 2)$ (mean $\mathrm{Rf}=13.6)$ counties. Reproduction on wheat was poor for the other Gallatin County population $(\mathrm{P} 1)(\mathrm{Rf}=2.8)$. Interactions were observed between populations and barley; populations from Chouteau, Dawson, and Hill counties were particularly virulent (mean $\mathrm{Rf}=8.1,3.8$, and 12.7 , respectively), whereas populations from Gallatin $(\mathrm{P} 2)$ and Yellowstone were nonvirulent (mean $\mathrm{Rf}=0.86$ and 0.76 , respectively; Table 2). There was also significant pathogenicity on lentils for the population from Dawson County (mean $\mathrm{Rf}=4.9$ ). Compared with their reproduction on wheat, the reproductive success for the different populations on barley ranged from a nonvirulent $5.8 \%$ to a virulent $88.3 \%$. For lentil, relative reproductive success ranged from a nonpathogenic $1.8 \%$ to a moderately virulent $63.6 \%$.

Quantification of males in pot culture populations. Male nematodes were observed in all of the pot cultures except for the population from Pondera County (Fig. 1). Their identity as P. neglectus was confirmed using morphology (Fig. 2) and by individual nematode extractions along with species-specific PCR assays and through comparisons of SSU rDNA sequences. Males in some cases exceeded $10 \%$ of the total RLN population. Populations of males averaged 7.5\% in Carter County, 3.1\% in Chouteau County, 3.2\% in Dawson County, $9.3 \%$ in Gallatin County P1, $1.0 \%$ in Gallatin County P2, $2.5 \%$ in Hill County, and $8.1 \%$ in Yellowstone County. An ANOVA detected no differences in the proportion of males across populations $(P=0.44)$.

Table 1. Nematodes identified from a statewide survey of cereal fields, conducted in 2015 and $2016^{\mathrm{a}}$

\begin{tabular}{|c|c|c|c|c|}
\hline \multirow[b]{2}{*}{$\begin{array}{l}\text { Nematode } \\
\text { genus/species }\end{array}$} & \multicolumn{2}{|c|}{2015} & \multicolumn{2}{|l|}{2016} \\
\hline & Nematodes/kg & $\begin{array}{c}\text { Fields } \\
\text { detected } \\
(\%)\end{array}$ & Nematodes/kg & $\begin{array}{c}\text { Fields } \\
\text { detected } \\
(\%)\end{array}$ \\
\hline $\begin{array}{l}\text { Pratylenchus } \\
\text { neglectus }\end{array}$ & 268 & 74.5 & 377 & 75.4 \\
\hline $\begin{array}{l}\text { Heterodera } \\
\text { filipjevi }\end{array}$ & 27 & 1.8 & 0.0 & 0.0 \\
\hline H. avenae & 27 & 18.1 & 14 & 7.5 \\
\hline $\begin{array}{l}\text { Tylenchorhynchus } \\
\text { spp. }\end{array}$ & 423 & 89.0 & 309 & 69.8 \\
\hline Tylenchus spp. & 552 & 72.7 & 59 & 22.6 \\
\hline $\begin{array}{l}\text { Helicotylenchus } \\
\text { spp. }\end{array}$ & 114 & 14.5 & 112 & 15.0 \\
\hline Xiphinema spp. & 0 & 0.0 & 2 & 1.8 \\
\hline Paratylenchus spp. & 10 & 10.9 & 4 & 1.8 \\
\hline Hoplolaimus spp. & 4 & 7.2 & 8 & 3.7 \\
\hline
\end{tabular}




\section{Discussion}

This is the first study to repeatedly demonstrate that populations of $P$. neglectus from different geographical regions display differential pathogenicity on barley. In particular, the populations from Hill, Dawson, and Choteau counties readily and repeatedly reproduced on barley, and populations from Gallatin (P2), Yellowstone, and Carter counties did not. Notably, this pathogenicity on barley did not correspond to relative pathogenicity on wheat. Our previous work showed that there is significant variation in resistance among barley cultivars (May et al. 2016), which may partially explain the inconsistency in reports on barley's susceptibility. The current work suggests that conflicting reports may also be the result of variation in pathogenicity among populations of this species. Reports on variation in reproductive success are common for P. neglectus (Griffin 1991; Griffin and Jensen 1997; Hafez et al. 1999). However, among those reports, the incorporation of positive controls is rare. This makes it unclear whether they describe differences in fecundity among nematode populations, differences in pathogenicity/ virulence for a particular host, or artifacts of the experimental system, as one author has suggested (Taylor 2000). With that said, a previous report demonstrated differential pathogenicity for $P$. neglectus on alfalfa, and two reports demonstrated differential pathogenicity for $P$. penetrans and $P$. neglectus on potato and tobacco (France and Brodie 1996; Hafez et al. 1999; Olthof 1968). Reported reproductive success of $P$. neglectus on barley varies widely across studies (Fanning et al. 2018; Sharma et al. 2011a, b). Given the variability reported by others, and the variability reported here, we suspect that differential pathogenicity on barley may be common. For that reason, we suggest that the designation of pathotype be adopted to describe those $P$. neglectus populations that are particularly well adapted to attacking barley.

The relative susceptibility of barley cultivars reported in these trials matches those of our previous report (May et al. 2016). In both reports, the barley cultivar Haxby was considered the most susceptible, whereas the other two barley cultivars (Harrington and Merit) were the most resistant (May et al. 2016). These results suggest that the variation in nematode pathogenicity on barley reported here is independent of variation in barley resistance. In many other cases, relative resistance among barley lines has been reliably reproduced, regardless of the nematode populations used (Fanning et al. 2018; May et al. 2016; Sheedy et al. 2015). These reports, as well as ours, suggest that the variation in resistance in barley will have widespread utility. With that said, a report suggests that this resistance is not universal, and some populations may be virulent to the more resistant genotypes (Sharma et al. 2011b). Our original barley testing was conducted using the Gallatin population (P1) also used for this trial, but for which there were no successful inoculations. The Gallatin (P1) culture has been used for many years and has high levels of fungal- and bacterial-affected nematodes (data not presented), which likely prevented its successful use. Unfortunately, this prevents direct comparisons for barley performances across our studies.

It is apparent based on these trials that barley may act as a significant host for $P$. neglectus depending on location and the nematode population. The consistently high Rf values on barley for the Hill, Dawson, and Chouteau populations, and the relative lack of reproduction for these populations on other rotational crops, suggest that pathotypes of $P$. neglectus will have a significant impact on

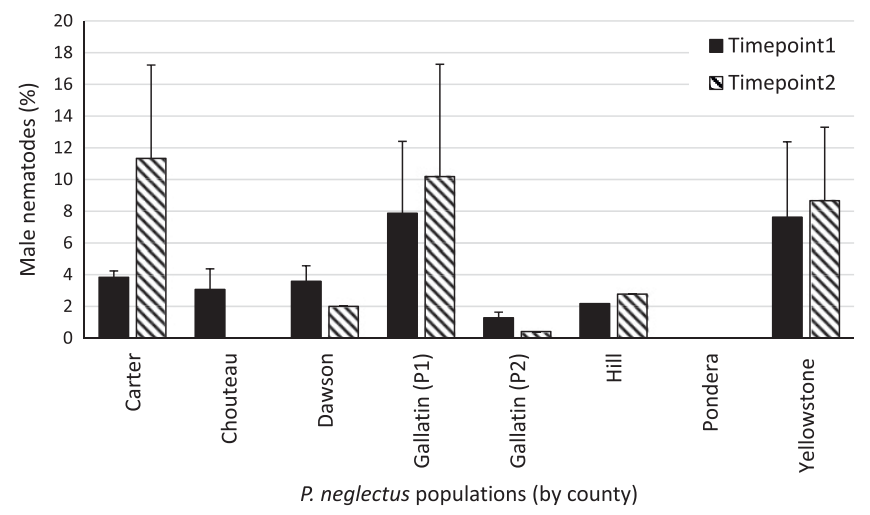

Fig. 1. Percentage of Pratylenchus neglectus nematodes counted from each population that were male, for timepoint 1 (in greenhouse from December 2016 to March 2017) and timepoint 2 (March to July 2017). The number of males was not significantly different between the two timepoints $(P=0.44)$.

Table 2. Variation in Pratylenchus neglectus reproduction factors (Rfs) across crops and populations ${ }^{\mathrm{a}}$

\begin{tabular}{|c|c|c|c|c|c|c|c|}
\hline \multirow[b]{2}{*}{ Population } & \multicolumn{6}{|c|}{ Crop (Cultivar) } & \multirow[b]{2}{*}{$\begin{array}{c}\text { Population } \\
\text { mean }^{\mathbf{b}}\end{array}$} \\
\hline & $\begin{array}{c}\text { Wheat } \\
\text { (Yellowstone) }\end{array}$ & Pea (Delta) & $\begin{array}{c}\text { Barley } \\
\text { (Haxby) }\end{array}$ & $\begin{array}{l}\text { Barley } \\
\text { (Merit) }\end{array}$ & $\begin{array}{c}\text { Barley } \\
\text { (Harrington) }\end{array}$ & $\begin{array}{c}\text { Lentil } \\
\text { (Richlea) }\end{array}$ & \\
\hline \multirow[t]{2}{*}{ Hill } & 44.3 & 0.5 & 13.6 & 13.6 & 11.6 & 0.8 & 14.1 \\
\hline & 2.39 & 0.31 & 2.05 & 1.74 & 1.30 & 0.45 & 1.37 \\
\hline \multirow[t]{2}{*}{ Carter } & 11.2 & 0.1 & 1.9 & 1.5 & 1.1 & 0.9 & 2.8 \\
\hline & 1.89 & 0.08 & 0.71 & 0.63 & 0.56 & 0.46 & 0.72 \\
\hline \multirow[t]{2}{*}{ Dawson } & 7.7 & 0.7 & 6.8 & 1.9 & 2.9 & 4.9 & 4.2 \\
\hline & 1.53 & 0.37 & 1.45 & 0.81 & 1.13 & 1.30 & 1.10 \\
\hline \multirow[t]{2}{*}{ Yellowstone } & 8.6 & 0.2 & 0.9 & 0.7 & 0.7 & 1.0 & 2.0 \\
\hline & 1.67 & 0.14 & 0.47 & 0.40 & 0.45 & 0.53 & 0.61 \\
\hline \multirow[t]{2}{*}{ Gallatin (P2) } & 13.6 & 0.4 & 1.0 & 0.8 & 0.8 & 0.4 & 2.8 \\
\hline & 1.27 & 0.22 & 0.41 & 0.44 & 0.42 & 0.23 & 0.50 \\
\hline \multirow[t]{2}{*}{ Chouteau } & 16.1 & 0.6 & 11.1 & 6.4 & 7.0 & 1.7 & 7.2 \\
\hline & 1.56 & 0.39 & 2.07 & 1.69 & 1.49 & 0.81 & 1.34 \\
\hline \multirow[t]{2}{*}{ Pondera } & 7.1 & 0.7 & 2.8 & 3.5 & 2.2 & 3.0 & 3.2 \\
\hline & 1.08 & 0.39 & 0.87 & 0.99 & 0.86 & 0.99 & 0.86 \\
\hline \multirow[t]{2}{*}{ Gallatin (P1) } & 2.8 & 0.7 & 3.8 & 1.3 & 1.9 & 3.4 & 2.3 \\
\hline & 0.63 & 0.42 & 1.29 & 0.76 & 0.94 & 1.21 & 0.88 \\
\hline \multirow[t]{2}{*}{ Crop mean ${ }^{c}$} & 13.9 & 0.5 & 5.2 & 3.7 & 3.5 & 2.0 & 4.8 \\
\hline & 1.50 & 0.29 & 1.16 & 0.77 & 0.89 & 0.93 & 0.92 \\
\hline
\end{tabular}

a Rfs were assessed for root lesion nematode (RLN) populations collected from different locations across Montana and grown in pot culture on wheat, pea, lentil, and barley crops. Mean Rfs across treatments are listed, with the natural $\log (\mathrm{Ln})$-transformed mean italicized below. A significant interaction was detected between populations and crops (analysis of variance, $F=2.88, P<0.001$ ), with Fisher's protected least significant difference (LSD) $(\alpha=0.05)$ on Ln-transformed data for the statistically significant RLN populations $\times$ crop interaction $=0.6$.

${ }^{\mathrm{b}}$ Fisher's protected LSD $(\alpha=0.05)$ on Ln-transformed data for RLN population means $=0.25$.

${ }^{c}$ Fisher's protected LSD $(\alpha=0.05)$ on Ln-transformed data for crop means $=0.22$. 
management practices for these fields. Significant variation was also observed on lentils, which warrants further exploration. The high Rf values on cereals for the Hill County population were not surprising, as the field from where it was collected has displayed a history of unusual population dynamics relative to crop rotations (data not presented). Prior to the survey, we had witnessed similar field dynamics for fields in Liberty County. The grower in this instance had abandoned cereal production as a result of the intransigence of the problem. Given our results, we urge caution in using barley as a management tool for $P$. neglectus in Montana, and we recommend caution for lentil as well. Our previous work showed that $P$. neglectus populations in field plots planted to barley, pea, and lentil have poor winter survival, possibly as a result of poor nematode health going into winter (May et al. 2016). In consideration of these results, trials assessing winter survival of these pathotypes would be the next step in assessing the practical impacts of this trait.

Unlike the results reported in 2006 and 2007, RLN populations in Montana are currently low. The differences in results between the two surveys with regard to $P$. neglectus is likely attributable to the widespread incorporation of legumes and barley (Long et al. 2014; Nagy 2001; NASS 2016) in rotation within the state. Legumes, particularly peas, were consistently resistant to RLN populations collected from across Montana, and their resistance to P. neglectus is well established in the literature (Riga et al. 2008; Smiley et al. 2013; Taylor et al. 2000). Given that pea acreage in Montana has increased from 54,600 hectares in 2005 to 246,000 in 2016 (NASS 2016), it is probable that peas have had a substantial impact on nematode populations in the state.

We observed unusually high male populations within our pot cultures relative to other reports (Handoo and Golden 1989; Loof 1960; Mahran et al. 2010; Nickle 1991; Sher and Allen 1953). Morphological and molecular results confirm their identity as $P$. neglectus. The highest relative populations appear associated with the least robust pot cultures, which matches reports of stress-induced male production (Bird 1971; McSorley 2003; Nicol 1996; Triantaphyllou 1973). Although not at these levels, others have witnessed males in culture of $P$. neglectus but few have documented and reported them (Nicol 1996). Although stress has been suggested as the reason for males in culture, other reports have detected Wolbachia bacterial parasites among Pratylenchus species (Juchault and Mocquard 1993; Rigaud 1997; Tortora et al. 2004; Werren 1997). These bacteria have been reported to decrease male production for infected insects, and may be

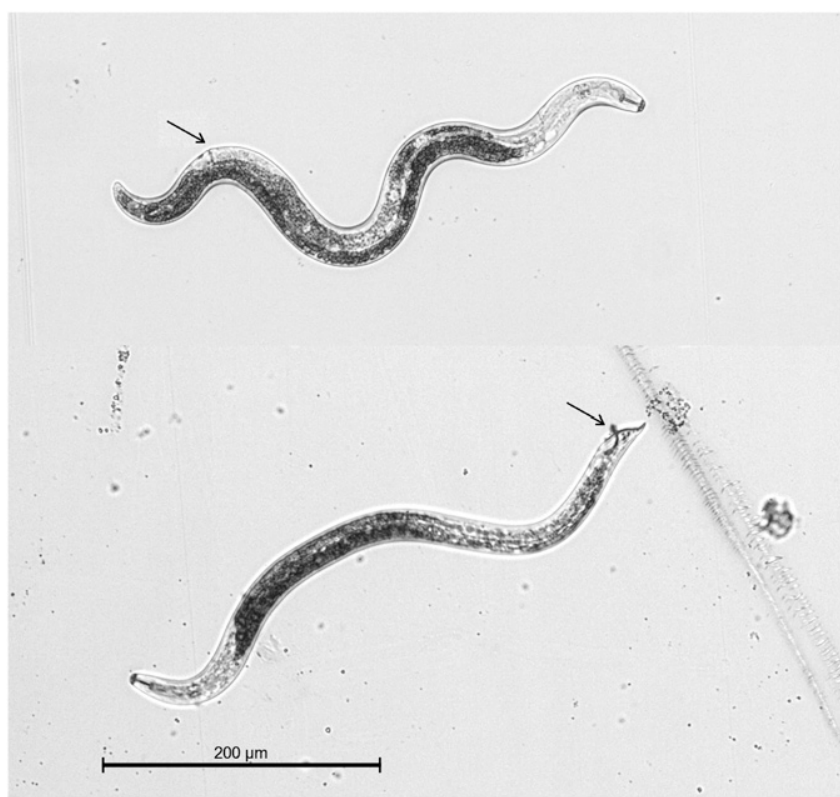

Fig. 2. Top, A female and Bottom, a male of Pratylenchus neglectus. Arrows point to the vulva and spicule for each, respectively. affecting the nematodes similarly. Nematode cultures are often pretreated with antibiotics that could eliminate natural Wolbachia populations, resulting in the increased production of males in culture. At this time, samples from these nematode populations are being tested for the bacterium's presence. Within the genus Pratylenchus, namely species $P$. scribneri, loss of meiotic cell division and a corresponding loss of males has been associated with doubling of chromosome numbers (Roman and Triantaphyllou 1969). Although unlikely, the large numbers of males we report may be associated with this type of genetic difference. Unfortunately, we had not documented the relative presence of males during the field survey, and we therefore cannot comment at this time on whether the males were an artifact of culturing methods or a characteristic of Montana's populations.

The presence of cereal cyst nematodes was uncommon in Montana and at this time does not represent a major risk for the state. Among the two cereal cyst species found, $H$. avenae was most common, with $H$. filipjevi only being detected in a previously reported field (Dyer et al. 2015). This is a particular relief for the state, as the latter species represents a unique risk to winter cereal production (Dyer et al. 2015). Among the other nematodes found in the survey, nematodes falling into the genera Tylenchorhynchus and Tylenchus were common, but their impacts on crops are unknown at this time.

In conclusion, RLN P. neglectus is the most prevalent and damaging nematode within the state. Its populations are considerably lower than those previously reported (May et al. 2016). This is attributed to the adoption of resistant and partially resistant rotational crops. Among locations where $P$. neglectus continues to persist, significant variation in pathogenicity on barley and lentils was observed. For these instances, we propose the adoption of the term "pathotypes" to describe these particularly virulent nematode populations. The pot cultures used for the greenhouse trials displayed significant populations of males. Why they occurred, and their significance, is unknown at this time.

\section{Acknowledgments}

We thank Dr. Richard Smiley (professor emeritus of Oregon State University) for sharing his knowledge, resources, and support, and Nathaniel Ellis for his contribution to the molecular work of this project.

\section{Literature Cited}

Al-Banna, L., Ploeg, A. T., Williamson, V. M., and Kaloshian, I. 2004. Discrimination of six Pratylenchus species using PCR and species-specific primers. J. Nematol. 36:142-146.

Barker, K. R., Carter, C. C., and Sasser, J. N. 1985. An Advanced Treatise on Meloidogyne. Volume II: Methodology. Department of Plant Pathology, North Carolina State University, Raleigh.

Bird, A. F. 1971. Specialized adaptations of nematodes to parasitism. Pages 35-49 in: Plant Parasitic Nematodes. B. Zuckerman, W. F. Mai, and R. A. Rohde, eds. Academic Press, New York, NY.

Cobb, N. A. 1918. Estimating the Nema Population of Soil, With Special Reference to the Sugar-Beet and Root-Gall Nemas, Heterodera schachtii Schmidt and Heterodera radicicola (Greef) Müller: And With a Description of Tylencholaimus aequalis n. sp. U.S. Government Printing Office, Washington, DC.

Devore, J., and Peck, R. 1997. Statistics: The Exploration and Analysis of Data. Sage, Thousand Oaks, CA.

Dyer, A. T., Al-Khafaji, R., Lane, T., Paulitz, T., Handoo, Z. A., Skantar, A. M. and Chitwood, D. J. 2015. First report of the cereal cyst nematode Heterodera filipjevi on winter wheat in Montana. Plant Dis. 99:1188.

Fanning, J., Linsell, K., McKay, A., Gogel, B., Santa, I. M., Davey, R., and Hollaway, G. 2018. Resistance to the root lesion nematodes Pratylenchus thornei and P. neglectus in cereals: Improved assessments in the field. Appl. Soil Ecol. 132:146-154.

Florini, D. A., Loria, R., and Kotcon, J. B. 1987. Influence of edaphic factors and previous crop on Pratylenchus spp. population densities in potato. J. Nematol. 19:85-92.

France, R. A., and Brodie, B. B. 1996. Characterization of Pratylenchus penetrans from ten geographically isolated populations based on their reaction on potato J. Nematol. 28:520-526.

Gair, R., Mathias, P. L., and Harvey, P. N. 1969. Studies of cereal nematode populations and cereal yields under continuous or intensive culture. Ann. Appl. Biol. 63:503-512.

Griffin, G. D. 1991. Differential pathogenicity of four Pratylenchus neglectus populations on alfalfa. J. Nematol. 23:380-385.

Griffin, G. D., and Jensen, K. B. 1997. Differential effects of Pratylenchus neglectus populations on single and interplantings of alfalfa grasses. J. Nematol. 29:82-89. 
Hafez, S. L., Al-Rehiayani, S., Thornton, M., and Sundararaj, P. 1999. Differentiation of two geographically isolated populations of Pratylenchus neglectus based on their parasitism of potato and interaction with Verticillium dahliae. Nematropica 29:25-36.

Handoo, Z. A., and Golden, A. M. 1989. A key and diagnostic compendium to the species of the genus Pratylenchus Filipjev, 1936 (lesion nematodes). J. Nematol. 21:202-218.

Handoo, Z. A., Palomares-Rius, J. E., Cantalapiedra-Navarrete, C., Liébanas, G., Subbotin, S. A., and Castillo, P. 2014. Integrative taxonomy of the stunt nematodes of the genera Bitylenchus and Tylenchorhynchus (Nematoda, Telotylenchidae) with description of two new species and a molecular phylogeny. Zool. J. Linn. Soc. 172:231-264.

Holterman, M., van der Wurff, A., van den Elsen, S., van Megen, H., Bongers, T., Holovachov, O., Bakker, J., and Helder, J. 2006. Phylum-wide analysis of SSU rDNA reveals deep phylogenetic relationships among nematodes and accelerated evolution toward crown clades. Mol. Biol. Evol. 23:1792-1800.

Jenkins, W. 1964. A rapid centrifugal-flotation technique for separating nematodes from soil. Plant Dis. Rep. 48:692.

Juchault, P., and Mocquard, J. P. 1993. Transfer of a parasitic sex factor to the nuclear genome of the host: A hypothesis on the evolution of sex-determining mechanisms in the terrestrial isopod Armadillidium vulgare Latr. J. Evol. Biol. 6:511-528.

Keil, T., Laubach, E., Sharma, S., and Jung, C. 2009. Screening for resistance in the primary and secondary gene pool of barley against the root-lesion nematode Pratylenchus neglectus. Plant Breed. 128:436-442.

Long, J. A., Lawrence, R. L., Miller, P. R., and Marshall, L. A. 2014. Changes in field-level cropping sequences: Indicators of shifting agricultural practices. Agric. Ecosyst. Environ. 189:11-20.

Loof, P. A. A. 1960. Taxonomic studies on the genus Pratylenchus (Nematoda). Tijdschrift Over Plantenziekten 66:29-90.

Loof, P. A. A., and Luc, M. 1990. A revised polytomous key for the identification of species of the genus Xiphinema Cobb, 1913 (Nematoda: Longidoridae) with exclusion of the $X$. americanum-group. Syst. Parasitol. 16:35-66.

Mahran, A., Tenuta, M., Shinners-Carenelly, T., Mundo-Ocampo, M., and Daayf, F. 2010. Prevalence and species identification of Pratylenchus spp. in Manitoba potato fields and host suitability of 'Russet Burbank.' Can. J. Plant Pathol. 32:272-282.

May, D. B., Johnson, W. A., Zuck, P. C., Chen, C. C., and Dyer, A. T. 2016. Assessment and management of root lesion nematodes in Montana wheat production. Plant Dis. 100:2069-2079.

McSorley, R. 2003. Adaptations of nematodes to environmental extremes. Fla. Entomol. 86:138-142.

Nagy, C. 2001. Agriculture Energy Use of Adaptation Options to Climate Change. A Report to the Prairie Adaptation Research Collaborative. Prairie Adaptation Research Collaborative, University of Regina, Regina, Saskatchewan, Canada.

NASS. 2016. National Agricultural Statistics Service. https://www.nass.usda.gov

National Center for Biotechnology Information. 2019. BLAST. https://blast.ncbi.nlm. nih.gov/Blast.cgi

Nickle, W. R. 1991. Manual of Agricultural Nematology. Marcel Dekker, New York, NY.

Nicol, J. M. 1996. The distribution, pathogenicity, and population dynamics of Pratylenchus thornei on wheat in South Australia. Ph.D. dissertation, University of Adelaide, Adelaide, South Australia.

Olthof, T. H. A. 1968. Races of Pratylenchus penetrans, and their effect on black root rot resistance of tobacco. Nematologica 14:482-488.

R Core Team. 2016. R: A Language and Environment for Statistical Computing. Vienna, Austria. https://www.R-project.org

RStudio Team. 2016. RStudio: Integrated Development for R. RStudio, Inc., Boston, MA. http://www.rstudio.com/

Riga, E., Porter, L. D., Mojtahedi, H., and Erickson, D. 2008. Pratylenchus neglectus, $P$. thornei, and Paratylenchus hamatus nematodes causing yield reduction to dryland peas and lentils in Idaho. Plant Dis. 92:979.

Rigaud, T. 1997. Inherited microorganisms and sex determination of arthropod hosts. Pages 81-102 in: Influential Passengers: Inherited Microorganisms and Arthropod Reproduction. S. L. O'Neill, A. A. Hoffmann, and J. H. Werren, eds. Oxford University Press, Oxford, UK.

Roman, J., and Triantaphyllou, A. C. 1969. Gametogenesis and reproduction of seven species of Pratylenchus. J. Nematol. 1:357-362.

Sasser, J. N. 1972. Physiological variation in the genus Meloidogyne as determined by differential hosts. EPPO Bull. 2:41-48.
Sharma, S., Sharma, S., Keil, T., Laubach, E., and Jung, C. 2011a. Screening of barley germplasm for resistance to root lesion nematodes. Plant Genet. Resour. 9:236-239.

Sharma, S., Sharma, S., Kopisch-Obuch, F. J., Keil, T., Laubach, E., Stein, N., Graner, A., and Jung, C. 2011b. QTL analysis of root-lesion nematode resistance in barley: 1. Pratylenchus neglectus. Theor. Appl. Genet. 122: 1321-1330.

Sheedy, J. G., McKay, A. C., Lewis, J., Vanstone, V. A., Fletcher, S., Kelly, A., and Thompson, J. P. 2015. Cereal cultivars can be ranked consistently for resistance to root-lesion nematodes (Pratylenchus thornei \& P. neglectus) using diverse procedures. Australas. Plant Pathol. 44:175-182.

Sher, S. A., and Allen, M. W. 1953. Revision of the genus Pratylenchus (Nematoda: Tylenchidae). Univ. Calif. Publ. Zool. 57:441-470.

Siddiqi, M. R. 1963. Four new species of the genus Tylenchus Bastian, 1865 (Nematoda) from North India. Parasitol. Res. 23:170-180.

Smiley, R. W. 2016. Cereal cyst nematodes: Biology and management in Pacific Northwest wheat, barley, and oat crops.Pacific Northwest Ext. Bull. 620. Oregon State University, Corvallis, OR.

Smiley, R. W., Machado, S., Gourlie, J. A., Pritchett, L. C., Yan, G., and Jacobsen, E. E. 2013. Effects of crop rotations and tillage on Pratylenchus spp. in the semiarid Pacific Northwest United States. Plant Dis. 97:537-546.

Smiley, R. W., Merrifield, K., Patterson, L.-M., Whittaker, R. G., Gourlie, J. A. and Easley, S. A. 2004. Nematodes in dryland field crops in the semiarid Pacific Northwest United States. J. Nematol. 36:54-68.

Smiley, R. W., and Nicol, J. M. 2009. Nematodes which challenge global wheat production. Pages 171-187 in: Wheat Science and Trade. B. F. Carver, ed. Vol. 10. Wiley-Blackwell, Ames, IA.

Smiley, R. W., Sheedy, J. G., and Easley, S. A. 2008. Vertical distribution of Pratylenchus spp. in silt loam soil and Pacific Northwest dryland crops. Plan Dis. 92:1662-1668.

Smiley, R. W., Whittaker, R. G., Gourlie, J. A., and Easley, S. A. 2005a. Pratylenchus thornei associated with reduced wheat yield in Oregon. J. Nematol. 37:45-54

Smiley, R. W., Whittaker, R. G., Gourlie, J. A., and Easley, S. A. 2005b. Suppression of wheat growth and yield by Pratylenchus neglectus in the Pacific Northwest. Plant Dis. 89:958-968.

Taylor, S. P. 2000. The root lesion nematode, Pratylenchus neglectus, in field crops in South Australia.Ph.D. dissertation, University of Adelaide, Adelaide, South Australia.

Taylor, S. P., Hollaway, G. J., and Hunt, C. H. 2000. Effect of field crops on population densities of Pratylenchus neglectus and $P$. thornei in southeastern Australia; Part 1: P. neglectus. J. Nematol. 32:591-599.

Thompson, A. L., Smiley, R. W., Paulitz, T. C., and Garland-Campbell, K. 2016. Identification of resistance to Pratylenchus neglectus and Pratylenchus thornei in Iranian landrace accessions of wheat. Crop Sci. 56:654-672.

Thompson, J. P., Owen, K. J., Stirling, G. R., and Bell, M. J. 2008. Root-lesion nematodes (Pratylenchus thornei and P. neglectus): A review of recent progress in managing a significant pest of grain crops in northern Australia. Australas. Plant Pathol. 37:235-242.

Thorne, G. 1961. Principles of Nematology. McGraw-Hill, New York, NY.

Tortora, G. J., Funke, B. R., Case, C. L., and Johnson, T. R. 2004. Microbiology: An Introduction. Benjamin Cummings, San Francisco, CA.

Triantaphyllou, A. C. 1973. Environmental sex differentiation of nematodes in relation to pest management. Annu. Rev. Phytopathol. 11:441-462.

Van den Berg, E., Tiedt, L. R., and Subbotin, S. A. 2014. Morphological and molecular characterisation of several Paratylenchus Micoletzky, 1922 (Tylenchida: Paratylenchidae) species from South Africa and USA, together with some taxonomic notes. Nematology 16:323-358.

Werren, J. H. 1997. Biology of Wolbachia. Annu. Rev. Entomol. 42:587-609.

Whitehead, A. G., and Hemming, J. R. 1965. A comparison of some quantitative methods of extracting small vermiform nematodes from soil. Ann. Appl. Biol. 55:25-38

Williams, K., Taylor, S., Bogacki, P., Pallotta, M., Bariana, H., and Wallwork, H. 2002. Mapping of the root lesion nematode (Pratylenchus neglectus) resistance gene Rlnn1 in wheat. Theor. Appl. Genet. 104:874-879.

Wouts, W. M., and Knight, K. W. L. 1993. Helicotylenchus vulgaris Yuen, 1964 (Nematoda: Hoplolaimidae): A new record for New Zealand. New Zeal. J. Zool. (Lond.) 20:133-136. 